\title{
Mechanical properties of concrete composed of sintered fly ash lightweight aggregate
}

\author{
Puput Risdanareni ${ }^{1, *}$, Januarti Jaya Ekaputri ${ }^{2}$, Ike Maulidiyawati ${ }^{1}$, and Poppy Puspitasari ${ }^{3}$ \\ ${ }^{1}$ Department of Civil Engineering, Faculty of Engineering, Universitas Negeri Malang, Indonesia \\ ${ }^{2}$ Department of Civil, Environmental and Earth Engineering, ITS, Sukolilo, Surabaya, Indonesia \\ ${ }^{3}$ Department of Mechanical Engineering, Faculty of Engineering, Universitas Negeri Malang, \\ Indonesia
}

\begin{abstract}
This paper investigates the effect of sintered fly ash lightweight aggregate as coarse aggregate substitution on the mechanical properties of concrete. The lightweight aggregate (LWA) was produced using the cold bonded method and then sintered at a temperature of $900^{\circ} \mathrm{C}$. An alkaliactivated system was applied as a binding agent of the LWA. Fly ash was used as precursor while sodium hydroxide and sodium silicate were employed as alkali activators. Three variations of the LWA dosage were performed, which were $0 \%, 50 \%$, and $100 \%$ of the volume of coarse aggregate in the concrete mixture. The mechanical properties of the concrete investigated in this research are the compressive strength and split tensile strength. The result showed that the mechanical properties of the concrete slightly decrease along with the increased dosage of the LWA in the mixture. However, employing sintered fly ash the LWA is proven as an effective solution in reducing the concrete density without sacrificing its strength.
\end{abstract}

\section{Introduction}

Research on recycling waste material into more valuable products such as cement replacement and artificial aggregates has become a massive issue in last decades. Currently, Indonesia has an abundant amount of fly ash as numerous power plants are operating in scattered areas to support the power demand of local residents [1]. As a by-product of coal combustion, fly ash causes environmental issues no recycling is undertaken. Recycling fly ash into artificial aggregates is one of the innovative solutions to reduce the amount of fly ash, as aggregates occupy more than $50 \%$ of the concrete volume.

Pelletized artificial aggregates can be produced by agglomerating the powder in a pan granulator with a certain amount of water and hardened by sintering, autoclaving or cold bonding treatment [2]. A previous research conducted by Gomathi found that the LWA produced with the cold-bonded method has a high-water absorption and high density that affects the concrete strength [3]. Sintering treatment at a temperature between $800^{\circ}$ to $1100^{\circ}$ could change the microstructure of the LWA [4]. The sintering could completely evaporate the retaining water in the LWA and form pores that will reduce the bulk density

* Corresponding author: puput.risdanareni.ft@um.ac.id 
of the LWA. As closed pores are created in this treatment, it reduces the number of water absorption in the LWA and increases the crushing resistance that absolutely contributes positively to the strength of concrete.

Parameters influencing the properties of pelletized aggregate are the speed of the pelletizer, the angle of the pelletizer, the moisture content and the duration of pelletisation [2]. Based on previous studies, the speed and the angle of the pan granulator is the most influencing factor to the resulting strength of the artificial aggregates [2]. Additional references state that the optimum angle for producing aggregates is $45^{\circ}-55^{\circ}$ with a speed of 35-55 rpm [3,5].

There are two binders that can be used to manufacture cold bonded aggregates, which are alkali-activated and cement based. Alkali-activated binder systems are eco-friendlier due to them diminishing the use of PC, as cement-based binder systems still require cement as a binder in small proportions. In alkali-activated binder systems, the concentration of sodium hydroxide and the alkali activator ratio play an important role in developing the properties of the paste [6]. The higher alkali the activator ratio and concentration of sodium hydroxide, the better properties of paste are produced [6]. However, a high alkali activator ratio will reduce the workability and lead to the flash setting of the paste [7]. Previous research recommends using an alkali activator ratio ranging from $1.5-2$, while the recommended sodium hydroxide concentration is between 6 to 10 molars $[6,7]$.

In order to investigate the influence of the LWA as a coarse aggregate substitution on the properties of structural lightweight concrete, three different dosages of LWA were applied, which are $0 \%, 50 \%$, and $100 \%$ of the total volume of the coarse aggregate. By applying this variation, an optimum dosage of the LWA in the concrete is expected to be obtained.

\section{Materials and method}

\subsection{Materials}

Fly ash class C obtained from Petrokimia Gresik was used as a precursor for artificial aggregate, while flake-shaped sodium hydroxide and a clear gel of sodium silicate was used as alkali activators. Sodium hydroxide was diluted in water a day prior to the mixing time to obtain a concentration of 10 Molar. The sodium silicate to sodium hydroxide ratio utilized in this study was 2 .

Sand and gravel from Lumajang were employed as a fine and coarse aggregates, while Portland cement type 1 produced by PT. Semen Indonesia was used as the material constituents to prepare the concrete mix.

\subsection{Method}

Artificial aggregates were manufactured using a pan granulator machine with a slope angle of $50^{\circ}$ and applying a spinning speed of $55 \mathrm{rpm}$. The fly ash powder was added to the pan and the alkali activator was sprayed gradually until it formed granulated aggregates. The amount of alkali-activated added into the mixture was obtained by trial attempts. The mix proportion between the alkali activator and fly ash is presented in Table 1. 
Table 1. The composition of fly ash and alkali activator.

\begin{tabular}{|c|c|c|c|c|}
\hline \multirow{2}{*}{ No } & \multirow{2}{*}{ Fly Ash (g) } & \multirow{2}{*}{$\begin{array}{c}\text { Alkali } \\
\text { activator (g) }\end{array}$} & \multicolumn{2}{|c|}{ Percentage (\%) } \\
\cline { 4 - 5 } & & 182 & 68,73 & 31,27 \\
\hline 1 & 582 & 165 & 66,8 & 33,2 \\
\hline 2 & 497 & 185 & 66,36 & 33,64 \\
\hline 3 & 550 & 172 & 67,61 & 32,39 \\
\hline 4 & 531 & 121 & 67,99 & 32,01 \\
\hline 5 & 378 & & 67,5 & 32,5 \\
\hline \multicolumn{3}{|c|}{ Mean } \\
\hline
\end{tabular}

Wet granulated artificial aggregates were then dried at room temperature for 24 hours and were stored in the oven at a temperature of $100^{\circ} \mathrm{C}$ for 24 hours. After the artificial aggregates were completely dry, the aggregates were sintered in a $900^{\circ} \mathrm{C}$ furnace for 6 hours and cooled at room temperature for 24 hours before use.

As a coarse aggregate substitution, the percentage of the LWA in the concrete mix was varied from $0 \%, 50 \%$, and $100 \%$. The mix design of all concrete specimens is presented in Table 2. All of the testings were conducted in the Laboratory of Material Testings and Laboratory of Structure, State University of Malang, using guidelines from ASTM.

Table 2. Concrete mix design.

\begin{tabular}{|c|c|c|c|}
\hline \multirow{2}{*}{$\begin{array}{c}\text { Materials } \\
(\%)\end{array}$} & A & B & C \\
\cline { 2 - 4 } & 8,72 & 8,72 & 8,72 \\
\hline Water & 17,45 & 17,45 & 17,45 \\
\hline Cement & 43,19 & 21,60 & 0 \\
\hline Coarse Aggregate & 0 & 21,60 & 43,19 \\
\hline LWA & 30,64 & 30,64 & 30,64 \\
\hline Fine Aggregate & 100 & 100 & 100 \\
\hline Total Volume & & & \\
\hline
\end{tabular}

\section{Result and discussion}

\subsection{Properties of sintered the LWA}

A set of laboratory testing was conducted in order to obtain the properties of the sintered LWA. The properties of the LWA are presented in Table 3. The bulk density and specific gravity of the sintered LWA is lower compared to conventional gravel. The water absorption of the sintered LWA is also lower compared to cold bonded LWA, which usually has a water absorption of more than $20 \%[3,8]$. This result is in good agreement with a previous research conducted by Corochanno, stating that sintering treatment is an effective way to reduce high water absorption on cold bonded LWA-fly-ash [9]. The abrasion value of the sintered LWA was also lower compared to the author's previous research, which means that the quality of the aggregate is higher than the previous the LWA result [10]. The lower abrasion value occurs due to the different material used and the higher sintering temperature applied. 
Table 3. Properties of sintered the LWA.

\begin{tabular}{|c|c|}
\hline Test & Result \\
\hline Bulk Density (g/cm3) & 1,08 \\
\hline Specific Gravity & 1,78 \\
\hline Water absorption (\%) & 1,5 \\
\hline Abrasion (\%) & 30,08 \\
\hline
\end{tabular}

\subsection{Slump test of fresh concrete}

A slump test was conducted in order to measure the level of workability of the concrete mix. The result of the slump test of all fresh concrete specimens is presented in Table 4. The higher the LWA content in the concrete, the higher slump value which is obtained. This is due to the lower water absorption of the LWA compared to gravel. Low water absorption of the LWA will reduce the amount of water that is absorbed into the aggregates' pores and results in a more slurry mixture. This finding agrees with the previous research which states that LWA affects the workability of the concrete. LWA with high water absorption requires additional water during the mixing process to create fresh concrete with good workability [5].

Table 4. Slump value of fresh concrete.

\begin{tabular}{|c|c|}
\hline Specimen's Code & $\begin{array}{c}\text { Slump value } \\
\text { (cm) }\end{array}$ \\
\hline A & 10 \\
\hline B & 12 \\
\hline C & 13 \\
\hline
\end{tabular}

\subsection{Density}

The density of the concrete was assessed using the ASTM C-642 guidelines. The result of the density test is displayed in Figure 1. The concrete density decreases as the LWA percentage increases. Specimen $\mathrm{C}$ which contains $100 \%$ LWA possesses the lowest density compared to the specimens. This result has met the expectation that a lower density of the LWA will cause a lower density of the concrete produced.

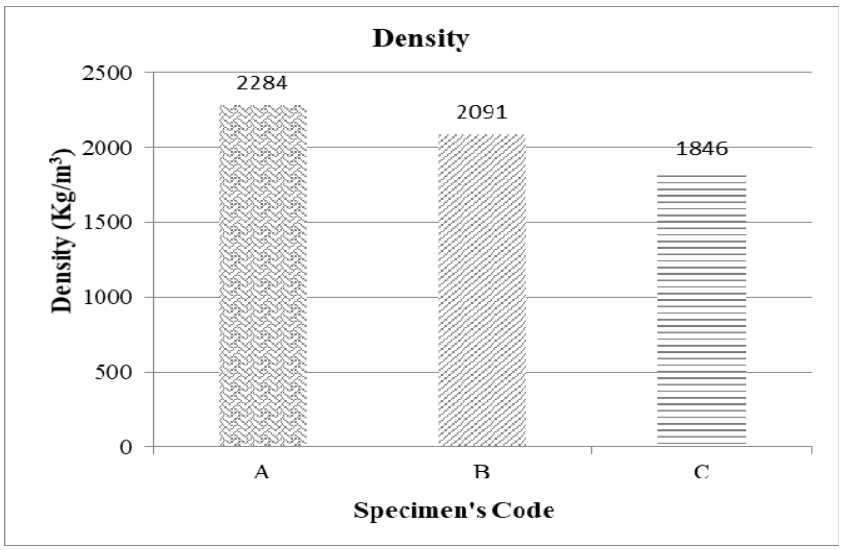

Fig. 1. Density of concrete. 


\subsection{Compressive strength}

The compressive strength data of all samples are shown in Figure 2. Sample A reaches the highest compressive strength compared to others. As expected, the compressive strength of concrete specimens decreases with increasing dosages of the LWA. This result has good agreement with the author's previous work which stated that the compressive strength of concrete decreases with the increase of the LWA content in the concrete mixture [10]. However, this fly ash-based LWA concrete has a higher compressive strength compared to metakaolin-based LWA concrete [10]. The higher compressive strength of this fly ashbased LWA concrete occurred due to the higher sintering temperature applied. Previous research conducted by Kockal also mentioned that the sintering temperature of the LWA played an important role in the properties of the produced concrete [11]. Heat treatment in certain temperature proofed to change the properties of the material such as porosity and water absorption $[11,4]$. The open pores of the aggregate change into close pores during heat treatment which lead to a decrease in water absorption and an increase in the strength of the aggregate. Thus, the changing properties of the sintered LWA will significantly impact the properties of the concrete produced.

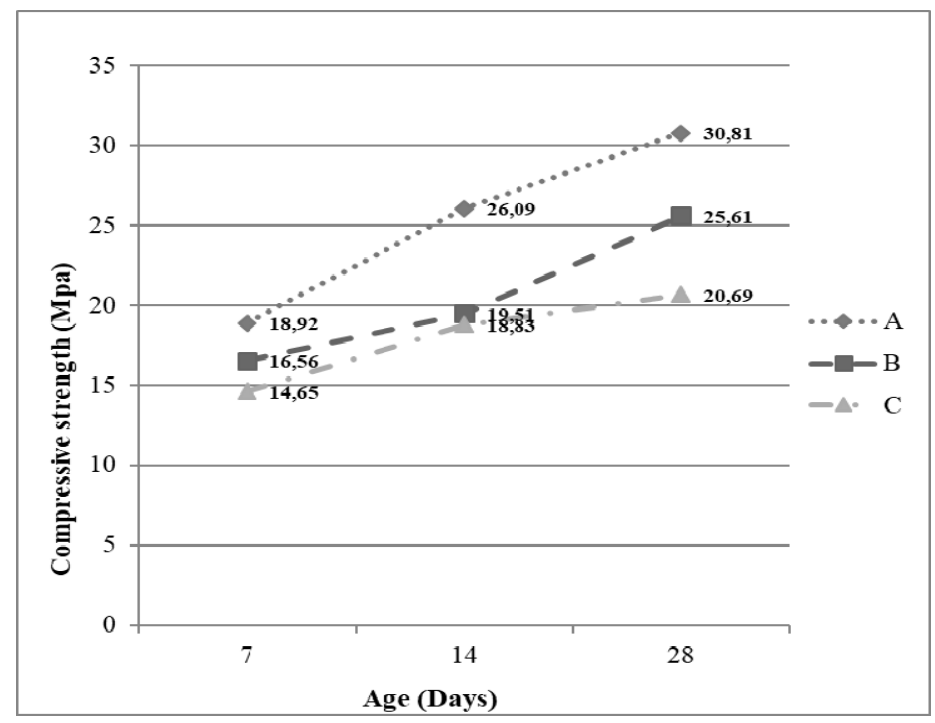

Fig. 2. Compressive strength of concrete.

\subsection{Split tensile strength}

The result of the split tensile strength is shown in Figure 3. The split tensile strength of the LWA concrete is from 2.93 to $3.67 \mathrm{MPa}$. Specimens containing a high amount of LWA exhibit the lowest split tensile strength. The higher the LWA content in the mixture, the lower the split tensile strength. The split tensile test result has a similar pattern to the compressive strength result. The average value of the split tensile strength is around $10 \%$ of its compressive strength. Adding the LWA into the concrete mixture has no significant effect on the split tensile strength of the concrete. This result is in good agreement with previous research by Gomathi, which stated that the split tensile strength did not depend on the LWA strength but depends on the mortar strength [3]. 


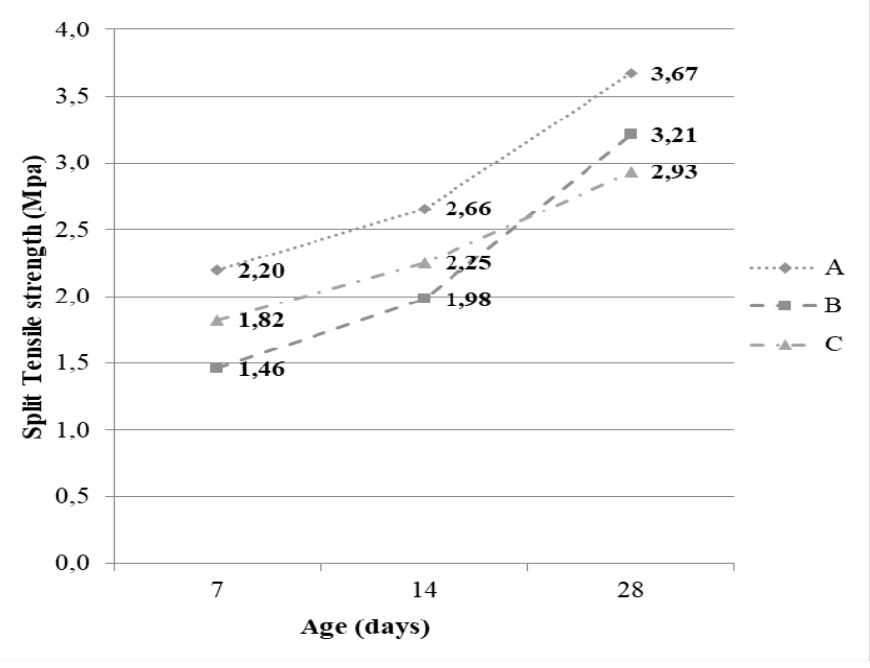

Fig. 3. Split tensile strength.

\section{Summary}

Replacing coarse aggregates with fly ash sintered LWA affects the mechanical and physical properties of the concrete, such as its density, slump, compressive strength, and split tensile strength. The total replacement of coarse aggregate with fly ash-based LWA could significantly reduce the concrete weight, so in extended works, the fly ash-based LWA is potentially used for developing lightweight concrete. At the current stage, the improved manufacturing method has fixed the microstructure of the LWA allowing the use of less mixing water to obtain higher concrete workability. Further investigations are still required to improve the performance of fly ash-based LWA so the replacement of the coarse aggregate does not compensate for the decrease in the compressive strength and split tensile strength of the concrete.

\section{References}

1. A. Hamanaka, H. Shimada, S. Ogata, T. Sasaoka, I. Miyajima, Journal of the Polish Mineral Engineering Society, 17, (2016)

2. K.I Harikrishnan, K. Ramamurthy, Waste Management, 26, 846-852, (2006)

3. P. Gomathi, A. Sivakumar, Construction and Building Materials, 77, 276-287, (2015)

4. R.N. Swamy, G.H. Lambert, The International Journal of Cement and Composite and Lightweight Concrete, 3, (1981)

5. P. Tang, M.V.A. Florea, H.J.H. Brouwers, Journal of Cleaner Production, 165, 13711384, (2017)

6. P. Risdanareni, J.J. Ekaputri, Triwulan, Mater. Sci. Forum, 803, (2015).

7. P. Risdanareni, J.J. Ekaputri, M. Mustafa Al bakri Abdullah, Applies Mechanics and Materials, 754-755, (2015)

8. P. Risdanareni, J.J. Ekaputri, Triwulan, AIP Conference Proceeding, 1887, (2017). 
9. G. Corrochano, B., Alonso-Azcarate, J., and Rodas, M., Constr. Build. Mater, 53, (2014)

10. P. Risdanareni, A.A. Choiri, B. Djatmika, P. Puspitasari, Civil Engineering Dimension, 19, (2017)

11. N.U. Kockal, T. Ozturan, Cement and Concrete Composites, 33, (2011) 